\title{
Copper oxide as efficient catalyst for oxidative dehydrogenation of alcohols with air
}

\author{
Poreddy, Raju; Engelbrekt, Christian; Riisager, Anders
}

Published in:

Catalysis Science \& Technology

Link to article, DOI:

10.1039/c4cy01622j

Publication date:

2015

Document Version

Peer reviewed version

Link back to DTU Orbit

Citation (APA):

Poreddy, R., Engelbrekt, C., \& Riisager, A. (2015). Copper oxide as efficient catalyst for oxidative dehydrogenation of alcohols with air. Catalysis Science \& Technology, 5(4), 2467-2477.

https://doi.org/10.1039/c4cy01622j

\section{General rights}

Copyright and moral rights for the publications made accessible in the public portal are retained by the authors and/or other copyright owners and it is a condition of accessing publications that users recognise and abide by the legal requirements associated with these rights.

- Users may download and print one copy of any publication from the public portal for the purpose of private study or research.

- You may not further distribute the material or use it for any profit-making activity or commercial gain

- You may freely distribute the URL identifying the publication in the public portal

If you believe that this document breaches copyright please contact us providing details, and we will remove access to the work immediately and investigate your claim 


\section{Copper Oxide as Efficient Catalyst for Oxidative Dehydrogenation}

\section{of Alcohols with Air}

Raju Poreddy ${ }^{*}$, Christian Engelbrekt ${ }^{*}$ and Anders Riisager ${ }^{\dagger *}$

${ }^{\dagger}$ Centre for Catalysis and Sustainable Chemistry, Department of Chemistry, Kemitorvet, Building 207, Technical University of Denmark, Dk-2800 Kgs. Lyngby, Denmark

* NanoChemistry, Department of Chemistry, Kemitorvet, Building 207, Technical University of Denmark, DK-2800 Kgs. Lyngby, Denmark

KEYWORDS: Oxidation, benzyl alcohol, $\mathrm{CuO}$ catalysis, nanoparticle synthesis, carbonyl compounds

ABSTRACT: The oxidative dehydrogenation of alcohols to carbonyl compounds was studied using $\mathrm{CuO}$ nanoparticle catalysts prepared by solution synthesis in buffered media. $\mathrm{CuO}$ nanoparticles synthesized in N-cyclohexyl-3-aminopropanesulfonic acid buffer showed high catalytic activity for the oxidation of benzylic, alicyclic and unsaturated alcohols to their corresponding carbonyl compounds with excellent selectivities. The observed trend in activity for conversion of substituted alcohols suggested a $\beta-\mathrm{H}$ elimination step to be involved, thus enabling a possible reaction mechanism for oxidative dehydrogenation of benzyl alcohols to be proposed. The use of $\mathrm{CuO}$ as an inexpensive and efficient heterogeneous catalyst under aerobic conditions provides a new noble metal-free and green reaction protocol for carbonyl compound synthesis.

\section{Introduction}


The oxidative dehydrogenation of primary and secondary alcohols to their corresponding carbonyl compounds is a fundamental reaction in nature and synthetic organic chemistry. Synthetic chemistry relies heavily on stoichiometric quantities of inorganic oxidants, ${ }^{1}$ whereas nature uses metal catalysis and oxygen as the terminal oxidant. ${ }^{2}$ Notably palladium, ${ }^{3}$ chromium(VI) reagents ${ }^{4,5}$ and manganese or ruthenium salts ${ }^{6,7}$ have attracted much attention as stoichiometric oxidants. However, the application of one or more equivalents of such relatively expensive and rather toxic oxidizing agents is an important factor limiting their usage in industry today. In addition, problems relating to corrosion and plating on reactor walls, handling, recovery and reuse of the catalyst represents serious process limitations. ${ }^{8}$ Therefore, the desire to replace stoichiometric oxidants with methodologies more resembling nature has gained much interest.

In the last few years numerous methods for oxidation of alcohols using heterogeneous catalysts have emerged, especially metal nanoparticles. ${ }^{9,10,11}$ Their use of either molecular oxygen or oxygen donating agents like hydrogen peroxide as the ultimate stoichiometric oxidant make these methods attractive and eco-friendly. In particular, molecular oxygen - or even air has been used as a cheap and abundant oxygen source for the oxidation of alcohols to carbonyl compounds. ${ }^{10}$ Although remarkable advances have been made in heterogeneous catalysis for the selective oxidation of alcohols, particularly with transition metals, only a limited number of catalysts are effective under mild reaction conditions. Heterogeneous catalytic systems are kinetically constrained by surface availability and metal-support interactions. ${ }^{12}$ Therefore, most research on aerobic oxidations using heterogeneous catalysts has focused mainly on highly active noble metals such as platinum, palladium and gold. ${ }^{13}$ Despite a hand full of reports on platinum and palladium as potential metals to catalyze oxidative dehydrogenation of alcohols, an 
overshadowing focus has emerged on gold chemistry since the pioneering work by Bond et al., ${ }^{14}$ Hutchings, ${ }^{15}$ Haruta et al. ${ }^{16}$ and Prati and Rossi ${ }^{17}$ utilizing supported gold nanoparticles. This abrupt interest is not only because gold is cheaper than its noble metal counterparts, but also that it circumvents most of the drawbacks associated with Pt and Pd. One example, is the fast deactivation rates attributed to aggregation of particles or leaching of noble metals during the oxidation and/or catalyst regeneration processes. ${ }^{18,19}$ This essentially holds true for the liquidphase oxidation of alcohols under aerobic conditions. Apart from cost considerations, the residues of noble metals (e.g. Pt and Pd) in pharmaceutical and nutritional products are prone to be highly harmful and problematic. ${ }^{20,21}$

Wang et al. $^{22}$ recently studied the activity of copper oxide supported gold nanoparticles and the influence of synthesis parameters on the transformation of alcohols to carbonyl compounds via oxidative dehydrogenation. They demonstrated that the catalytic performance of gold strongly depended on the preparation method, $\mathrm{pH}$ value and stirring rate by presumably influencing the electronic state and particle size of the gold nanoparticles as well as the structure of the support. With this system there was no need for additional base to promote the reaction, which is otherwise often the case. This is good in terms of waste minimization and product recovery, but higher loading of the rather expensive noble metal gold was required to obtain moderate conversion. Hence, more sustainable solutions based on earth abundant, cheap, harmless and stable metals to replace noble metals would be desirable. In this connection, application of catalysts based on the relatively inexpensive metals $\mathrm{Ag}, \mathrm{Cu}$ and $\mathrm{Fe}$ have increasingly been explored for aerobic and non-aerobic oxidations under ambient conditions. ${ }^{23}$ Thus, silver nanoparticles or clusters supported on different metal oxides have been reported to be potential catalysts for the oxidative dehydrogenation of alcohols to carbonyl compounds. ${ }^{10,24}$ 
Likewise, copper ${ }^{25,26}$ and iron ${ }^{27,28}$ have gained importance in recent years and iron oxides though harmless, less toxic, and cheaper - are not better catalysts than copper for oxidation reactions of alcohols at low temperatures. ${ }^{29}$ Other homogeneous copper catalysts ${ }^{30}$ and metallic copper catalysts with styrene as hydrogen acceptor $^{31}$ are also reported for the alcohol dehydrogenations.

As mentioned above, Wang et al. ${ }^{22}$ have showed that $\mathrm{CuO}$ is an effective support material for $\mathrm{Au}$ in the catalytic oxidation of alcohols. However, they also reported that $\mathrm{CuO}$ alone cannot catalyze the reaction being nearly inactive, since the adsorption of benzyl alcohol onto the $\mathrm{CuO}$ surface was too weak to be activating and that pure $\mathrm{CuO}$ could not activate the $\mathrm{O}_{2}$ molecule. Copper, because of its characteristic promoting ability was also involved in bi-metallic catalysis particularly with gold ${ }^{32}$ and platinum ${ }^{33}$. Our interest in the synthesis of carbonyl compounds as well as non-noble metal catalysis prompted us to examine a range of supported copper-based catalysts for alcohol oxidation.

In this work, we have elaborated our previous synthesis procedure for $\mathrm{CuO}$ nanoparticles and the structure and morphology of the $\mathrm{CuO}$ catalysts have been thoroughly characterized. We further demonstrate that $\mathrm{CuO}$ as a non-noble metal oxide is a highly efficient heterogeneous catalyst in the oxidation of alcohols under mild reaction conditions using oxygen as a green terminal oxidant.

\section{Experimental Section}

\subsection{Chemicals}

$\mathrm{CuCl}_{2} \cdot 2 \mathrm{H}_{2} \mathrm{O}$ (p.a., Riedel-de Haën), $N$-cyclohexyl-3-amino-propanesulfonic acid (CAPS) ( $\geq 98 \%$, Sigma-Aldrich), 2-( $N$-morpholino)ethanesulfonic acid (MES) hydrate (99.5\%, Sigma- 
Aldrich), $\mathrm{KOH}(\geq 85 \%$, Sigma-Aldrich) were used as received for the synthesis of $\mathrm{CuO}$ nanoparticles. All the substrates for the catalytic oxidations were purchased from Sigma Aldrich and used without any further purification.

\subsection{Catalyst preparation}

$\mathrm{CuO}$ nanoparticles were synthesized following a modification of our previously reported procedure. ${ }^{34}$ It was found that $\mathrm{pH}$ about 11 is optimal for aqueous $\mathrm{CuO}$ synthesis. Therefore, CAPS $(\mathrm{pKa}=10.4)$ was chosen to replace MES $(\mathrm{pKa}=6.15)$ as the buffer. Preparation was done by first dissolving $4.432 \mathrm{~g}$ of CAPS (nanoparticles denoted "CAPS-CuO") or $3.905 \mathrm{~g}$ of MES (nanoparticles denoted "MES-CuO") in $950 \mathrm{~mL}$ Millipore water and adjusting the $\mathrm{pH}$ to 11 for CAPS-CuO and 12 for MES-CuO with $\mathrm{KOH}$. The buffer was preheated to $95{ }^{\circ} \mathrm{C}$ under stirring before rapid addition of $50 \mathrm{~mL}$ solution of $0.682 \mathrm{~g} \mathrm{CuCl}_{2}$ in Millipore water. Final concentrations of buffer and $\mathrm{CuCl}_{2}$ were 20 and $4 \mathrm{mM}$, respectively. The initially bright blue $\mathrm{CuCl}_{2}$ solution immediately turned green indicating intermediate formation of hydrated copper hydroxide and after few seconds the solution turned dark brown as $\mathrm{CuO}$ was formed. Heating was maintained for 30 min after which the solution was allowed to cool to room temperature with stirring. Stirring was terminated and the particles left to sediment overnight. The $\mathrm{CuO}$ nanoparticles were filtered under vacuum with a $0.2 \mu \mathrm{m}$ Nylon membrane filter from Gelman Sciences (New York, USA) and washed several times with water. The remaining water was expelled from the product by washing with ethanol, and then dried under vacuum to remove excess ethanol leaving a brittle film that could easily be recovered from the membrane. The dry powder was lightly crushed and left under vacuum overnight.

Two different samples of $\mathrm{Cu}_{2}(\mathrm{OH})_{3} \mathrm{Cl}$ was tested as reference systems. A- $\mathrm{Cu}_{2}(\mathrm{OH})_{3} \mathrm{Cl}$ was prepared in a similar procedure to the $\mathrm{CuO}$ nanoparticles but in $1.5 \mathrm{~L}$ batches and final 
concentrations of MES and $\mathrm{CuCl}_{2}$ of 50 and $10 \mathrm{mM}$, respectively. The buffer was adjusted to $\mathrm{pH}$ 11 and preheated to $80{ }^{\circ} \mathrm{C}$ before $\mathrm{CuCl}_{2}$ addition. The synthesis of $\mathrm{B}-\mathrm{Cu}_{2}(\mathrm{OH})_{3} \mathrm{Cl}$ was achieved by heating a mixture of $\mathrm{Cu}_{2}(\mathrm{OH})_{2} \mathrm{CO}_{3}$ and $\mathrm{CuCl}_{2}$ as described previously. ${ }^{34}$

\subsection{Catalyst characterization}

The textural properties of the samples were determined by nitrogen physisorption analysis using a Micromeritics (Norcross, GA USA) ASAP 2020 with an Automated Gas Adsorption Surface area and Porosimetry Analyzer at liquid nitrogen temperature. The samples were outgassed in vacuum at $200{ }^{\circ} \mathrm{C}$ prior to measurement. The surface areas were determined by the BrunauerEmmett-Teller (BET) method.

X-ray powder diffraction (XRD) spectra were measured on a Huber (Rimsting, Germany) G670 diffractometer with a Guinier imaging plate camera operated in transmission mode with $\mathrm{Cu} K_{\alpha 1}(\lambda=1.54 \AA \hat{)})$ irradiation from a focusing quartz monochromator. The samples were fixed between two pieces of Scotch tape and rotated during data collection. The diffraction patterns of the samples were recorded at room temperature in the $2 \theta$ range of $3-100^{\circ}$ in steps of $0.005^{\circ}$.

Transmission electron microscopy (TEM) studies were performed on a Tecnai T20 G2 and Titan instrument from FEI Company (Hillsboro, OR USA) operated at 200 and $120 \mathrm{kV}$, respectively. The Titan was fitted with a field-emission electron source and a spherical aberration corrector on the condenser lens system. The samples were redispersed in ethanol by ultrasonication and deposited on plain or holey carbon-coated $\mathrm{Cu}$ grids from Agar Scientific (Stansted, UK).

X-ray photoelectron spectroscopy (XPS) was performed on a XPS-ThermoScientific using Al-Ka $(1486 \mathrm{eV})$ as exciting $\mathrm{X}$-ray source. The pressure of the analysis chamber was 
maintained at $2 \cdot 10^{-10}$ mbar during measurement. The XPS measurements were performed in the electron binding energy ranges corresponding to copper $2 p$ and oxygen 1 s core excitations.

The reducibility of the copper catalysts was investigated by temperature programmed reduction using $\mathrm{H}_{2}\left(\mathrm{H}_{2}\right.$-TPR). The samples were pretreated in $20 \mathrm{~mL} / \mathrm{min}$ of $10 \% \mathrm{O}_{2} / \mathrm{He}$ mixture gas flow at $500{ }^{\circ} \mathrm{C}$ for $1 \mathrm{~h}$ and then cooled down to $30{ }^{\circ} \mathrm{C}$ and flushed out with $\mathrm{He}$ for $1 \mathrm{~h}$. Then the samples were heated from 30 to $600{ }^{\circ} \mathrm{C}$ at a ramp of $10{ }^{\circ} \mathrm{C} / \mathrm{min}$ in $60 \mathrm{~mL} / \mathrm{min}$ of $4 \% \mathrm{H}_{2} / \mathrm{Ar}$ mixture gas flow. The water formed during reduction with $\mathrm{H}_{2}$ was trapped using a dry ice cold trap and the hydrogen consumption was continuously monitored with a TCD detector.

The amount of copper leached into the reaction liquor after the catalytic reactions was determined by inductively coupled plasma mass spectrometry (ICP-MS). Toluene was removed from $1 \mathrm{~mL}$ of filtrate after $24 \mathrm{~h}$ reaction by drying and the remnant, containing any leached copper, was dissolved in $5 \mathrm{~mL} 0.1 \mathrm{M}$ nitric acid for analysis. $4 \mathrm{mg}$ of fresh com-CuO was similarly dissolved in $5 \mathrm{~mL} 0.1 \mathrm{M}$ nitric acid.

Thermogravimetric analysis of catalysts was performed on a TGA/DSC 1 STAR system from Mettler Toledo in $80 \mathrm{~mL} / \mathrm{min} \mathrm{N}_{2}$ flow and a heating rate of $10^{\circ} \mathrm{C} / \mathrm{min}$.

Attenuated total reflectance Fourier transform infrared spectroscopy (ATR-FTIR) measurements were performed on a Thermo Scientific Nicolet iS5 and Specac Golden Gate (Waltham, MA, USA) with a diamond plate. The spectra were recorded in the range of 4000-400 $\mathrm{cm}^{-1}$ with a resolution of $2 \mathrm{~cm}^{-1}$.

\subsection{General oxidation procedure}

In a typical oxidation reaction, the copper catalyst $(60 \mathrm{mg}, 0.75 \mathrm{mmol}, 75 \mathrm{~mol} \%$ with respect to the substrate) was dispersed in a glass tube in $3 \mathrm{~mL}$ toluene facilitated by ultrasonication followed by the addition of substrate $(1 \mathrm{mmol})$ and internal standard anisole $(0.1 \mathrm{mmol})$. The 
tube containing the reaction mixture was connected to a reaction station which provided stirring and heating at $100{ }^{\circ} \mathrm{C}$ for $22-24 \mathrm{~h}$. The reaction was carried out under atmospheric pressure of air with oxygen as the oxidant.

\subsection{Product analysis}

During the reactions samples were periodically collected, filtered and analyzed by GC-FID (Agilent, 6890N) and GC- MS (Agilent, 6850N) with an HP-5 capillary column (Agilent, J\&W) using $\mathrm{N}_{2}$ as the carrier gas. The amounts of substrates and reaction products were quantified using anisole as an internal standard. The reported conversions were calculated from the conversion of alcohol.

\section{Results and Discussion}

\subsection{Catalyst preparation}

In our previous work, copper mineral nanoparticles $\left(\mathrm{CuO}\right.$ and $\left.\mathrm{Cu}_{2}(\mathrm{OH})_{3} \mathrm{Cl}\right)$ were selectively synthesized by controlling $\mathrm{pH}$ with a buffered reaction medium. The optimal conditions for $\mathrm{CuO}$ formation was determined to be $95{ }^{\circ} \mathrm{C}$ and $\mathrm{pH} 11$. For the current work, the synthesis was further optimized for the preparation of the $\mathrm{CuO}$ catalysts. A Good's buffer with a pKa close to $\mathrm{pH} 11$ was chosen (CAPS, $\mathrm{pKa}=10.4)$ and the reactant concentrations increased providing welldefined $\mathrm{CuO}$ nanoparticles in less than $30 \mathrm{~min}$.

\subsection{Catalyst screening}

The oxidation of benzyl alcohol was investigated in the presence of a range of commercial and synthesized copper catalysts in toluene at $100{ }^{\circ} \mathrm{C}$ and atmospheric pressure of air. The reaction proceeded smoothly to afford the corresponding aldehydes with good to excellent yields. Table 1 compiles the catalytic performance obtained of $\mathrm{Cu}(\mathrm{I})$ and $\mathrm{Cu}(\mathrm{II})$ oxides, chlorides and 
hydroxychlorides (Table 1, entries 1-10) for aldehyde formation under the given reaction conditions.

The $\mathrm{CuO}$ synthesized in different buffered media (i.e. CAPS-CuO and MES-CuO) showed activity and selectivity superior to other tested catalysts for benzaldehyde formation (Table 1, entries 1 and 2). Hence, MES-CuO with an excellent selectivity of $>99 \%$ yielded $71 \%$ benzaldehyde whereas CAPS-CuO afforded $>99 \%$ yield of benzaldehyde. Over-oxidation or aldehyde disproportionation products such as acids, esters, and alcohols were not observed during the reaction.

Table 1. Catalyst screening for aerobic oxidation of benzyl alcohol ${ }^{[a]}$

\begin{tabular}{lllll}
\hline Entry & Catalyst & $\begin{array}{l}\mathrm{S}_{\mathrm{BET}} \\
{\left[\mathrm{m}^{2} \mathrm{~g}^{-1}\right]}\end{array}$ & $\begin{array}{l}\text { Conversion }^{[\mathrm{b}]} \\
{[\%]}\end{array}$ & $\begin{array}{l}\text { Selectivity } \\
{[\%]}\end{array}$ \\
\hline 1 & CAPS-CuO & 46.2 & $>99$ & $>99$ \\
2 & $\mathrm{MES}-\mathrm{CuO}$ & 37.4 & 71 & $>99$ \\
3 & com-CuO & 13.1 & 69 & 91 \\
4 & com-CuO ${ }^{[\mathrm{c}]}$ & n.d. ${ }^{[\mathrm{d}]}$ & 4 & $>99$ \\
5 & $\mathrm{~A}-\mathrm{Cu}_{2}(\mathrm{OH})_{3} \mathrm{Cl}$ & 20.1 & 23 & $>99$ \\
6 & ${\mathrm{~B}-\mathrm{Cu}_{2}(\mathrm{OH})_{3} \mathrm{Cl}}$ & 5.1 & 29 & $>99$ \\
7 & $\mathrm{CuO} \mathrm{bulk}$ & n.d. ${ }^{[\mathrm{d}]}$ & 3 & $>99$ \\
8 & $\mathrm{Cu}_{2} \mathrm{O} \mathrm{bulk}$ & 0.10 & 2 & $>99$ \\
9 & $\mathrm{CuCl}_{10}$ & n.d. $^{[\mathrm{d}]}$ & 5 & $>99$ \\
$11^{[\mathrm{e}]}$ & - & 5.3 & 16.7 & $>99$ \\
\hline
\end{tabular}

[a] Reaction conditions: Benzyl alcohol ( $2 \mathrm{mmol})$, anisole $(0.2 \mathrm{mmol})$, toluene $(6 \mathrm{~mL}), 120 \mathrm{mg}$ catalyst, $24 \mathrm{~h}, 100{ }^{\circ} \mathrm{C}$, atmospheric air. [b] Conversion was evaluated by GC and GC-MS using 
anisole as internal standard. [c] Reduced com-CuO using $\mathrm{H}_{2}\left(10 \%\right.$ in $\left.\mathrm{N}_{2}\right)$. [d] Not detectable. [e] Control experiment without catalyst.

The commercial copper oxide nanopowder (com-CuO) with a particle size of $<50 \mathrm{~nm}$ and a surface area of $13.1 \mathrm{~m}^{2} \mathrm{~g}^{-1}$ (Table 1, entry 3 ) performed best of the commercial catalysts (entries 7-10). The lack of significant activity of the bulk $\mathrm{CuO}$ (entry 7) may be ascribed to the low BET surface area. Though com-CuO was more active than the other commercial catalysts, it was less selective. Thus, over-oxidation of benzaldehyde to benzoic acid followed by esterification seemed unavoidable with com-CuO resulting in lower selectivity (91\%) than CAPS- and MES$\mathrm{CuO}$.

The formation of the over-oxidation product benzyl benzoate can also be obtained by oxidation of the hemiacetal (a product resulting from the reaction of benzyl alcohol and benzaldehyde). Copper(II) chloride (entry 10) showed some activity for benzaldehyde formation, but catalysed also the nucleophilic exchange reaction with benzyl alcohol yielding benzyl chloride and alkylation of toluene (solvent) with benzyl alcohol in significant amounts. The catalysis of side reactions was not observed for the synthesized hydroxychlorides (entries 5 and 6). Their activity was improved compared to $\mathrm{CuCl}_{2}$ but still not comparable to the synthesized oxides. com- $\mathrm{CuO}$ was reduced at $300{ }^{\circ} \mathrm{C}$ by $\mathrm{H}_{2}\left(10 \%\right.$ in $\left.\mathrm{N}_{2}\right)$ to its metallic state and studied for the same reaction (entry 4). The reduction of com-CuO did not improve the activity but instead reduced it to only $4 \%$. In fact, only copper in the oxidation state +2 showed any significant activity for the oxidation of benzyl alcohol. A control experiment without added catalyst was further performed and, as expected, no substantial amount of benzaldehyde was formed under the given reaction conditions (entry 11). 

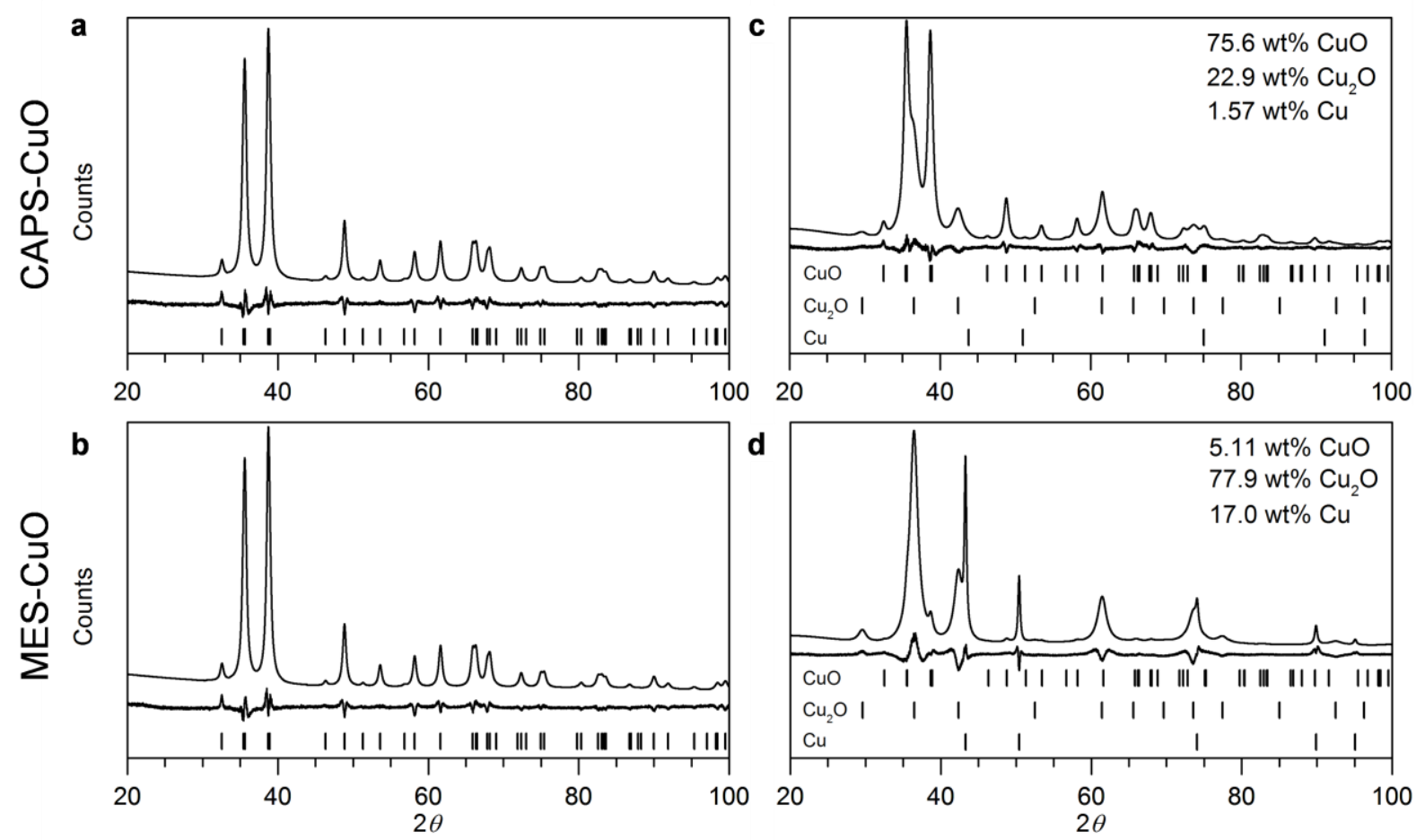

Fig. 1. Rietveld refinement of fresh (a) CAPS-CuO and (b) MES-CuO catalysts and the corresponding profiles for spent (c) CAPS-CuO and (d) MES-CuO after $22 \mathrm{~h}$ of oxidation of benzyl alcohol in toluene at $100{ }^{\circ} \mathrm{C}$ in air. Each graph includes the refined pattern (top line), the difference between the refinement and raw data (bottom line) and Bragg positions of crystallographic phases of $\mathrm{CuO}, \mathrm{Cu}_{2} \mathrm{O}$ and metallic copper (black bars).

\subsection{Characterization of CAPS-, MES- and com-CuO}

Detailed characterization of the catalysts (especially CAPS-CuO which exhibited superior performance) was undertaken to correlate their activity and structural properties. The crystal structure and morphology of the synthesized nanostructures were characterized by XRD and TEM. Fig. 1a and -c displays the fitted XRD patterns of CAPS-CuO and MES-CuO, respectively. Both catalysts showed clear tenorite $\mathrm{CuO}$ structure and no other detectable crystalline phases. This is supported by Rietveld refinement of the spectra confirming previous findings that no redox chemistry was involved in the synthesis. ${ }^{34}$ The refinement provided 
crystallite sizes of 17.5 and $18.8 \mathrm{~nm}$ for CAPS-CuO and MES-CuO, respectively. Apart from the small variation in crystallite size, no differences were detected with XRD. The purity of the assynthesized CAPS-CuO was further confirmed by ICP-MS measurements of the dissolved catalyst showing no other metal impurities (SI Fig. 1).

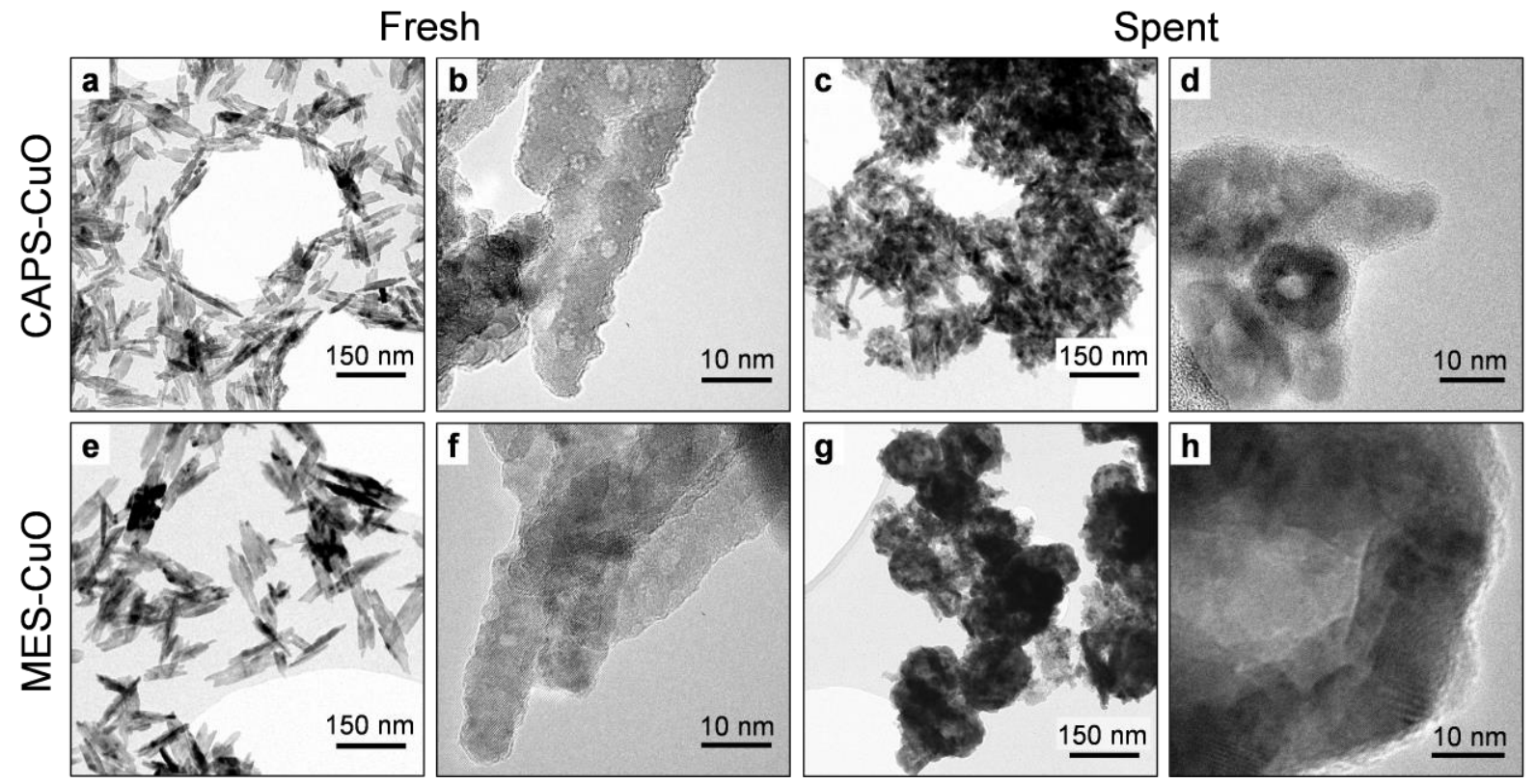

Fig. 2. TEM micrographs of the as-synthesized (a-b) CAPS-CuO and (e-f) MES-CuO, and the corresponding spent (c-d) CAPS-CuO and (g-h) MES-CuO after $24 \mathrm{~h}$ of benzyl alcohol conversion at $100{ }^{\circ} \mathrm{C}$ in air. TEM images of as-received com-CuO are shown in SI Fig. 2.

The morphology, i.e. shape, size and roughness, of the $\mathrm{CuO}$ nanoparticles was investigated with TEM which is supplementary to the crystallite information from XRD. High and low magnification TEM micrographs of CAPS- and MES-CuO are presented in Fig. 2. Both catalysts consist of flat, elongated nanoparticles up to $200 \mathrm{~nm}$ long, $100 \mathrm{~nm}$ wide and roughly 10 nm thick (Fig. 2a and 2e). The particles are seemingly assembled by rods via side-to-side attachment and overall smaller in CAPS-CuO than MES-CuO. The rod-like structures and rough 
surfaces are evident in Fig. $\mathbf{2 b}$ and $\mathbf{2 f}$. Due to the aggregating nature of the nanoparticles on the TEM grids it was difficult to obtain electron diffraction from single particles. Instead, the nanoscale crystal structure was studied by high-resolution (HR) TEM. HR micrographs of several single nanoparticles from CAPS- and MES-CuO were obtained and the corresponding FFTs indexed (Fig. 3 and SI Table 1).
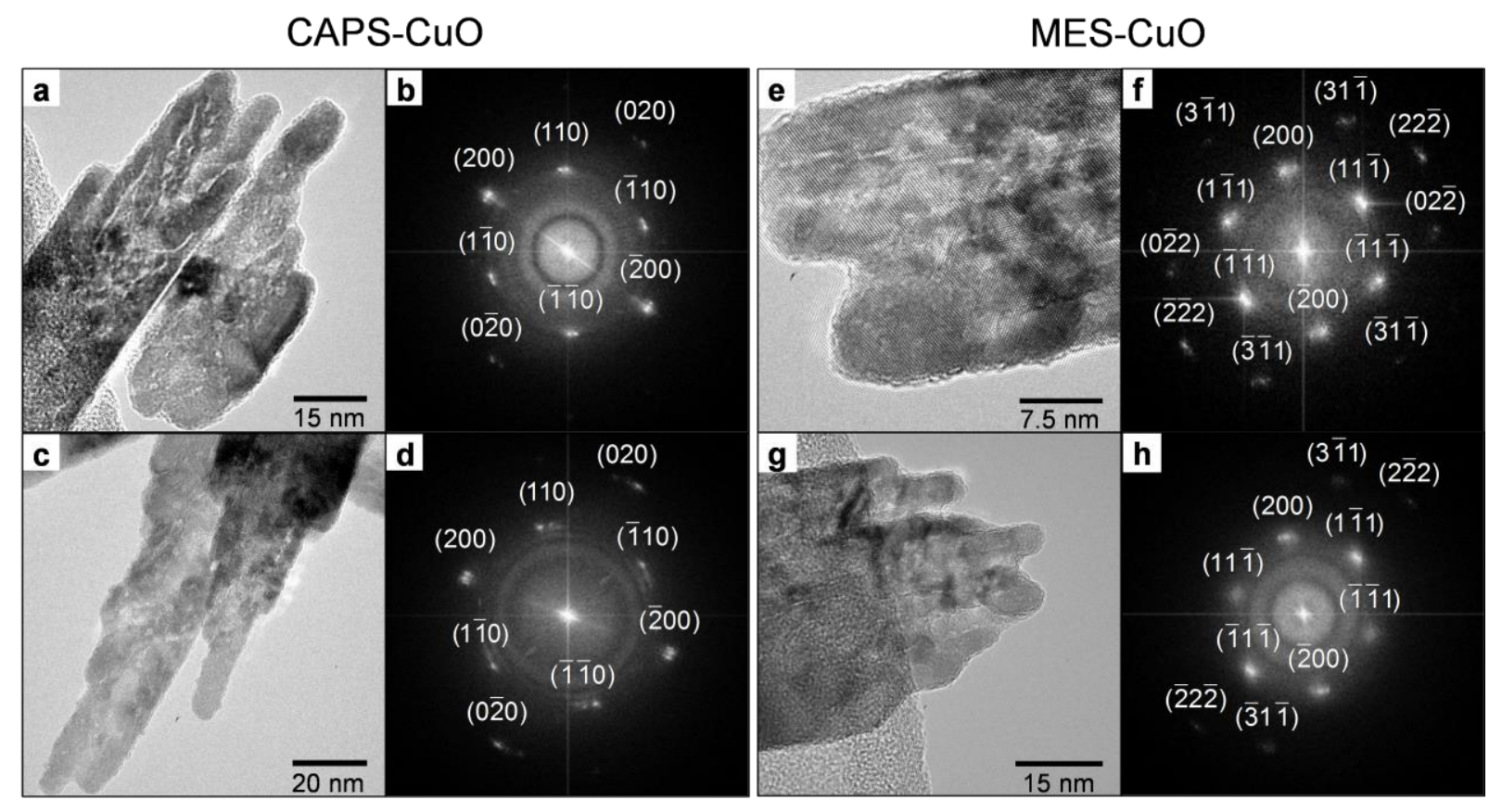

Fig. 3 Representative HR-TEM micrographs of CAPS- and MES-CuO with corresponding indexed FFTs.

The facets making up to the main surface areas were determined from the zone axis with the assumption that the flat structures were lying roughly perpendicular to the beam. The crystal directions corresponding to the long, intermediate and short axes of the sheets were identified as [010], [100] and [001] for CAPS-CuO and [01-1], [100] and [011] for MES-CuO, respectively. These observations indicate that while the overall crystallite size and nanoparticle shape were similar for the two structures the different chemical environments during synthesis may have led to changes in the relative surface energies of the main facets and oriented attachment 
mechanisms. The slight differences in exposed facets may contribute to the differences in observed activity (Table 1) as the main facets may represent different inherent activities towards the dehydrogenation of benzyl alcohol. Similar anisotropic growth and $\left[\mathrm{OH}^{-}\right]$dependency has previously been observed. ${ }^{35,36,37,38}$

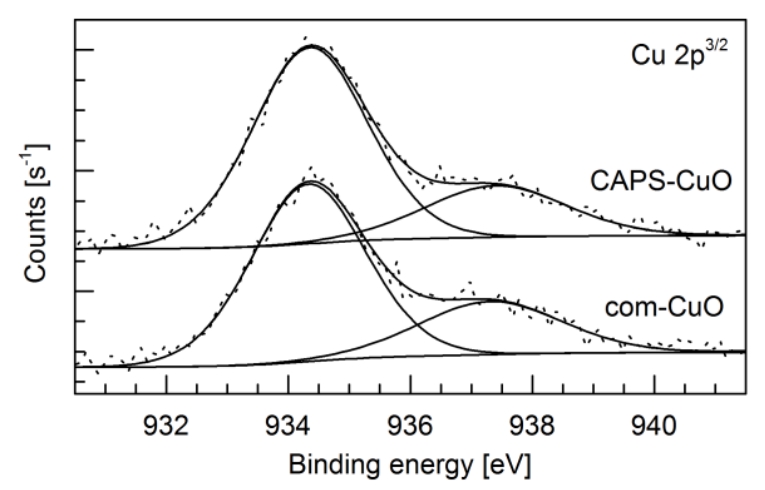

Fig. 4. High resolution XPS core level spectra of the $\mathrm{Cu} 2 \mathrm{p}$ transition for CAPS-CuO (top) and com- $\mathrm{CuO}$ (bottom).

Fig. 4 shows the XPS spectra corresponding to the $\mathrm{Cu} 2 \mathrm{p}$ transition for CAPS- and com$\mathrm{CuO}$. The peaks at binding energies of about 934.2 and $953.0 \mathrm{eV}$ (full spectrum, SI Fig. 3) are due to the spin-orbit doublet of the $\mathrm{Cu} 2 \mathrm{p}$ core level transition. The $\mathrm{Cu} 2 \mathrm{p}^{3 / 2}$ transition included in Fig. 4 of both CAPS- and com-CuO can be deconvoluted giving two main contributions located around 934.2 and $937.5 \mathrm{eV}$. The relatively sharp band located at $934.2 \mathrm{eV}$ is tentatively assigned to $\mathrm{CuO},{ }^{39}$ while the second peak located at $937.5 \mathrm{eV}$ is allocated to $\mathrm{Cu}$ (II) species with different environment or coordination. ${ }^{40}$ Full range spectra of both CAPS- and com-CuO are shown in SI Fig. 3 with spin-orbit coupled $\mathrm{Cu} 2 \mathrm{p}^{1 / 2}$ transition $(953.0 \mathrm{eV})$ between two well defined satellite structures at around 945.1 and $956 \mathrm{eV}$.

McIntyre et al. ${ }^{41}$ has reported that the main $\mathrm{Cu} 2 \mathrm{p}^{3 / 2}$ transition for metallic copper and $\mathrm{Cu}_{2} \mathrm{O}$ appears at energy levels lower than $933 \mathrm{eV}$, while it shifts to values higher than $933 \mathrm{eV}$ for 
$\mathrm{Cu}(\mathrm{II})$ species. The $\mathrm{Cu} 2 \mathrm{p}^{3 / 2}$ transition for $\mathrm{Cu}(0)$ and $\mathrm{Cu}(\mathrm{I})$ was reported to occur at the same binding energy $932.5 \mathrm{eV}$, about $1.3 \mathrm{eV}$ below the main core level line. ${ }^{41,42}$ According to this assignment, the profiles shown in Fig. 4 reveal neither $\mathrm{Cu}(0)$ nor $\mathrm{Cu}(\mathrm{I})$ in synthesized and commercial copper oxide. A satellite peak located above the core level line $(945.1 \mathrm{eV})$ is prominent in both $\mathrm{CuO}$ samples (SI Fig. 3), but hardly visible in $\mathrm{Cu}(\mathrm{I}) \mathrm{XPS}^{42}$ This observation confirms that the oxidation state of $\mathrm{Cu}$ in both catalysts is +2 and is consistent with the XRD results. However, the energy of the $\mathrm{Cu} 2 \mathrm{p}^{3 / 2}$ transition does not allow unequivocally to determine the oxidation state of copper unless the Auger parameter $(\alpha)$ is determined. ${ }^{40}$ Furthermore, a relatively narrow line $(\mathrm{FWHM}=1.8 \mathrm{eV})$ at around $532.5 \mathrm{eV}$ representing $\mathrm{O} 1 \mathrm{~s}^{1 / 2}$ transition was observed for both of the catalysts ${ }^{43}$ (SI Fig. 4). This transition appears to arise mainly from one type of oxygen. It has been reported that the $\mathrm{CuO}$ phase likely has three types of oxygen components, namely $\mathrm{O}-\mathrm{Cu}, \mathrm{HO}-\mathrm{Cu}$, and surface oxygen (O-surf) with binding energies around 529.1, 530.6, and $531.5 \mathrm{eV}$, respectively. ${ }^{43}$ This clearly suggests that both catalysts (CAPS- and com-CuO) have a high degree of surface oxygen.

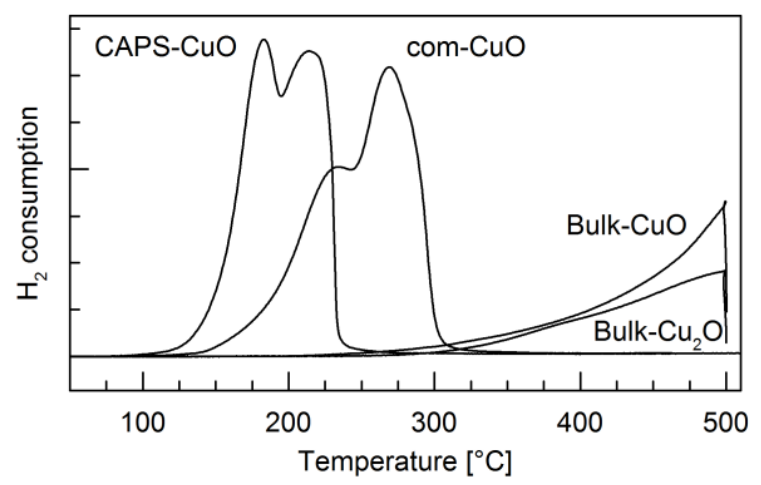

Fig. 5. $\mathrm{H}_{2}$-TPR profiles of different copper catalysts.

Additional information about the copper species in the CAPS- and com-CuO catalysts was obtained by $\mathrm{H}_{2}$-TPR (Fig. 5). The $\mathrm{H}_{2}$ consumption was also studied for bulk $\mathrm{CuO}$ and $\mathrm{Cu}_{2} \mathrm{O}$ 
to elucidate how bulk copper species behave differently from highly dispersed surface $\mathrm{Cu}$ species on CAPS- and com-CuO. Interestingly, the reduction temperatures for CAPS- and com$\mathrm{CuO}$ were very low compared with that of bulk $\mathrm{CuO}$ and $\mathrm{Cu}_{2} \mathrm{O}$, suggesting that bulk species was reduced at higher temperatures than $\mathrm{Cu}(\mathrm{II})$ on the surface. The low temperature peaks of TPR due to highly dispersed $\mathrm{CuO}$ and/or $\mathrm{Cu}(\mathrm{II})$ species have also been observed for supported $\mathrm{CuO}^{44,45}$ Van der Grift et al. $^{46}$ and Robertson et al. ${ }^{47}$ further supported this observation concluding that the highly dispersed copper oxide species are more easily reduced than bulk CuO. CAPS-CuO seemed to have no bulk copper oxide and was therefore reduced at very low temperatures, while com- $\mathrm{CuO}$ comprises both dispersed and bulk-like $\mathrm{CuO}$ resulting in a shift in reduction peak to higher temperatures without exhibiting true bulk behavior. At this point, it is worth noting that the specific surface area of highly dispersed CAPS-CuO $\left(46.2 \mathrm{~m}^{2} \mathrm{~g}^{-1}\right)$ was substantially higher than com-CuO $\left(13.1 \mathrm{~m}^{2} \mathrm{~g}^{-1}\right)$. Hence, more active $\mathrm{Cu}(\mathrm{II})$ species were available providing increased catalytic activity.

\subsection{Optimization of reaction conditions}

CAPS-CuO as the best performing catalyst was used to optimize the reaction conditions. In order to investigate the effect of the atmosphere, the reaction was tested under air, argon, pure oxygen and wet oxygen conditions (Fig. 6).

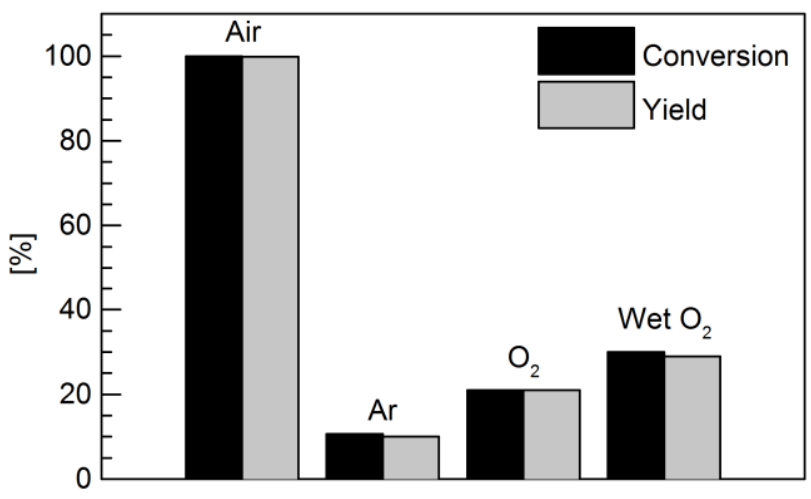


Fig. 6. Effect of atmosphere on benzyl alcohol oxidation. Reaction conditions: Benzyl alcohol (1 $\mathrm{mmol})$, anisole $(0.1 \mathrm{mmol})$, toluene $(3 \mathrm{~mL}), 60 \mathrm{mg}$ CAPS-CuO catalyst, $24 \mathrm{~h}, 100{ }^{\circ} \mathrm{C}$.

Reaction in atmospheric air resulted in higher yields (>99\%) than inert $(10 \%)$, pure oxygen $(21 \%)$ and wet oxygen $(28 \%)$ conditions. These results underlined that oxygen was essential for the reaction, but also suggested that only a moderate amount of oxygen was beneficial for the reaction. Increased oxygen concentration could lead to saturation of the surface by oxygen. As a result, the rate of aldehyde formation could be lowered. Furthermore, the wet oxygen experiment confirmed the activity to increase by almost $50 \%$ compared to dry oxygen conditions. XRD results of the four spent catalysts revealed an interesting observation that copper oxide was partially reduced only in air, while no reduction apparently occurred under the conditions where only low or insignificant conversions were obtained (SI Fig. 5a).

The catalytic activity of the prepared CAPS-CuO was tested using atmospheric air at different temperatures to further optimize the reaction conditions. As shown in Table 2, the conversion of benzyl alcohol to benzaldehyde after $24 \mathrm{~h}$ increased from 11 to $>99 \%$ when the temperature was increased from 40 to $100^{\circ} \mathrm{C}$. The catalyst was observed to be more selective for benzaldehyde at higher temperatures with a change in selectivity from 95 to $99 \%$ in $24 \mathrm{~h}$.

Table 2. Influence of temperature on the activity of catalyst $\mathrm{CAPS}-\mathrm{CuO}{ }^{[a]}$

\begin{tabular}{lllll}
\hline Entry & Temp. $\left[{ }^{\circ} \mathrm{C}\right]$ & Conversion $^{[\mathrm{b}]}[\%]$ & Selectivity $^{[\mathrm{b}]}[\%]$ & Yield $^{[\mathrm{b}]}[\%]$ \\
\hline 1 & 40 & $11(5)$ & $95(>99)$ & $10(5)$ \\
2 & 60 & $21(9)$ & $97(99)$ & $20(9)$ \\
3 & 80 & $49(18)$ & $98(98)$ & $48(18)$ \\
4 & 100 & $>99(36)$ & $>99(97)$ & $>99(35)$ \\
\hline
\end{tabular}


[a] Reaction conditions: Benzyl alcohol $(1 \mathrm{mmol})$, anisole $(0.1 \mathrm{mmol})$, toluene $(3 \mathrm{~mL}), 60 \mathrm{mg}$ catalyst, $24 \mathrm{~h}$, atmospheric oxygen. [b] After $24 \mathrm{~h}$ and after $6 \mathrm{~h}$ in parentheses.

The effect of catalyst loading was further studied with CAPS-CuO at $100{ }^{\circ} \mathrm{C}$ in air with catalyst mass between 10 to $60 \mathrm{mg}$ (Fig. 7). Not surprisingly, the overall reaction rate was found to increase with the amount of catalyst and even $20 \mathrm{mg}$ ( $25 \mathrm{~mol} \%$ ) of the catalyst gave $75 \%$ yield in $24 \mathrm{~h}$. Furthermore, the selectivity of the reactions seemed independent of the catalyst loading with only insignificant amounts (1\%) of esterification product (benzyl benzoate) observed for the reaction run with $40 \mathrm{mg}$ of catalyst. In terms of reaction time, conversion and selectivity a loading of $60 \mathrm{mg}$ of CAPS-CuO catalyst was considered optimal and thus maintained for further experiments. This corresponds to $75 \mathrm{~mol} \%$ and approaches stoichiometric amounts. However, this is less important since it is a non-precious metal and can be successfully regenerated (see section 3.8).

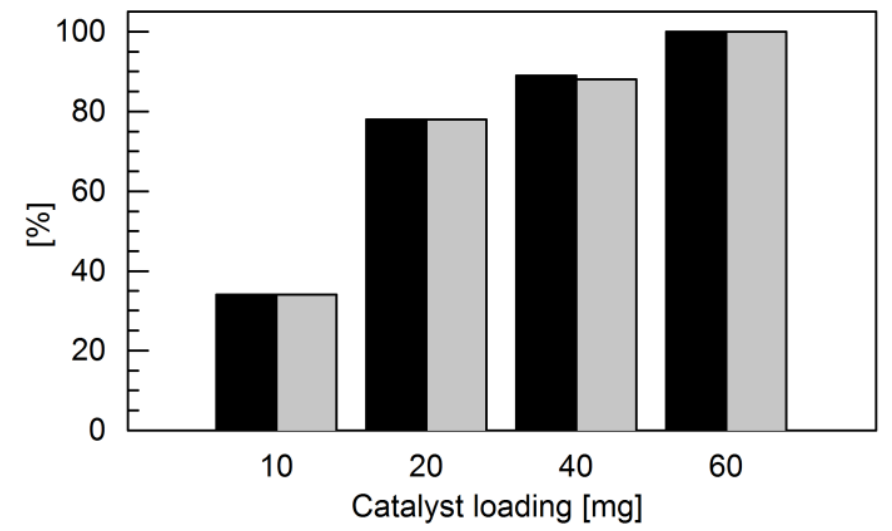

Fig. 7. Effect of CAPS-CuO catalyst loading on oxidation of benzyl alcohol showing conversion (black) and yield (grey). Reaction conditions: Benzyl alcohol (1 mmol), anisole $(0.1 \mathrm{mmol})$, toluene ( $3 \mathrm{~mL}), 24 \mathrm{~h}, 100{ }^{\circ} \mathrm{C}$, atmospheric air. 
Fig. 8 shows the time-dependent catalytic performance of commercial $\mathrm{CuO}(\mathrm{com}-\mathrm{CuO})$ in comparison with the prepared $\mathrm{CuO}$ (CAPS- and MES-CuO). The initial reaction rate was low and similar for the three $\mathrm{CuO}$ catalysts, indicating that an induction period prevailed before reaching full activity. Thus, after $4 \mathrm{~h}$ of reaction the conversion of benzyl alcohol had reached only about $11 \%$ for all of the catalysts. However, at prolonged reaction time of $24 \mathrm{~h}$ the CAPS$\mathrm{CuO}$ provided $>99 \%$ yield of benzaldehyde, whereas the reaction rate was lower for the MESand com-CuO yielding only 69 and $70 \%$ benzaldehyde in $24 \mathrm{~h}$, respectively. The origin of the induction period could relate to a low initial surface-substrate interaction, heating of the solvent from room temperature to the target temperature, or catalyst wetting processes though this is not presently disclosed.

The stability of the catalysts can be closely related to the ability to maintain a high amount of $\mathrm{Cu}(\mathrm{II})$ avoiding transformation into $\mathrm{Cu}(\mathrm{I})$ and especially metallic $\mathrm{Cu}$, both of which have shown poor activity. The phase transition in CAPS- and MES-CuO and the distribution of $\mathrm{CuO}, \mathrm{Cu}_{2} \mathrm{O}$ and $\mathrm{Cu}$ metal, respectively, was monitored by XRD of the catalysts after $24 \mathrm{~h}$ of reaction (Fig. 1b and 1d). Catalyst CAPS-CuO was reduced partially with time (SI Fig. 5b) to $\mathrm{Cu}_{2} \mathrm{O}$, but not to an extent that could affect the reaction rate. The reduction was more pronounced in the case of MES-CuO catalyst, where only about $5 \mathrm{wt} \%$ of the copper remained as $\mathrm{CuO}$. 


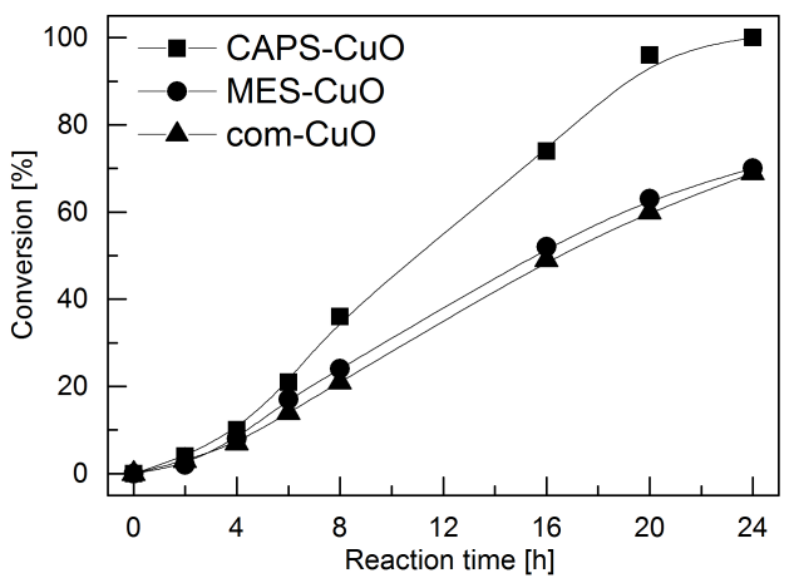

Fig. 8. Conversion of benzyl alcohol with time over CAPS-CuO, MES-CuO, and com-CuO (commercial) catalysts. Reaction conditions: Benzyl alcohol (1 mmol), anisole (0.1 mmol), toluene $(3 \mathrm{~mL})$, catalyst $(60 \mathrm{mg}) 24 \mathrm{~h}, 100{ }^{\circ} \mathrm{C}$, atmospheric air.

The partial reduction of the $\mathrm{CuO}$ nanoparticles led to a change in morphology. The spent MES-CuO catalyst showed a large number of spherical, hollow structures around $100 \mathrm{~nm}$ in size (Fig. 2g). These were not present in the spent CAPS-CuO sample where only a few $10 \mathrm{~nm}$ spherical structures were found. It is clear that the slight difference in the synthesis procedure of the two copper oxides had great influence on the stability resulting in the superior performance of CAPS-CuO. This agrees with the HR-TEM results showing that the surface of CAPS-CuO is dominated by highly stable [001] facets. ${ }^{36,37}$ com-CuO resulted most likely in lower catalytic activity compared to the CAPS-CuO catalyst, because of its substantially lower surface area and absence of well-defined crystallinity (SI Fig. 2).

\subsection{Versatility of the reaction}

With the optimized reaction conditions established, the scope of aldehyde and/or ketone formation was examined with the CAPS-CuO catalyst. The substrates were carefully chosen to demonstrate the versatility of the reaction between saturated and unsaturated alcohols, aromatic 
and alicyclic alcohols, and substituted and unsubstituted alcohols (Table 3). The results confirmed that conversion of a broad range of alcohols was achieved with excellent selectivity $\geq 98 \%$ except for cinnamyl alcohol which only gave $61 \%$ selectivity at full conversion (Table 3 , entry 6) due to benzopyran formation (cyclization product). Thus, importantly the unsaturated alcohols allyl alcohol and cinnamyl alcohol (entries 6 and 13) yielded the desired aldehydes in good to excellent yields without loss of the carbon double bonds. The saturated aliphatic alcohols (entries 14 and 15) afforded very low yields of aldehyde but in excellent selectivity, suggesting that longer reaction time (or higher temperature) than compared to benzyl alcohol was needed to reach high yields.

To study the effect of ring strain on the activity cyclopentanol, cyclohexanol and cycloheptanol (entries 10-12) were also included as substrates. Interestingly, the activity towards these alcohols increased markedly with ring size, i.e. the number of carbon atoms in the ring. This was most pronounced in the case of cycloheptanol where $>99 \%$ yield of cycloheptanal was obtained. These results are well-matched with previously reported results by Wang et al., ${ }^{22}$ that tension in the ring increases with the size leaving the molecule more reactive. Furthermore, Wang et al. also reported that para-substituents had no obvious effect on the catalytic oxidation rates of benzyl alcohols with $\mathrm{Au} / \mathrm{CuO}$ under the given conditions. This is understandable if benzyl carbocation intermediates are not generated of which stability (and thus reactivity) would strongly depends on the para substituent. Arguably, a reaction mechanism including $\beta-\mathrm{H}$ elimination is still proposed in the work. In our work, different para-substituted benzyl alcohols were also tested as substrates in the $\mathrm{CuO}$ catalyzed oxidation reaction (Table 3, entries 2-5).

A significant decrease in substrate conversion was observed with the substituents in the following order: $p-\mathrm{OCH}_{3}(100 \%)>p-\mathrm{CH}_{3}(98 \%)>p-\mathrm{Cl}(75 \%)>p-\mathrm{CF}_{3}(61 \%)$. This suggests a 
linear free energy relationship between the activity and the Brown-Okamoto $\left(\sigma^{+}\right)$parameter, where substrates with electron donating groups $\left(p-\mathrm{OCH}_{3}\right.$ and $\left.p-\mathrm{CH}_{3}\right)$ are more reactive than with electron withdrawing groups $\left(p-\mathrm{Cl}\right.$ and $\left.p-\mathrm{CF}_{3}\right)$. These results clearly indicate that the reaction proceeded via a rate determining $\beta-\mathrm{H}$ elimination step resulting in the formation of an intermediate benzyl carbocation. Such elimination step is also generally found to be the rate determining step. ${ }^{48,49}$ The slight decrease (1-2\%) found in selectivity to benzylic aldehydes (Table 3, entries 1-5) was due to the formation of the corresponding esters. Such esters may be formed by condensation of the benzyl alcohols with benzoic acids (from over-oxidation of aldehyde or aldehyde disproportionation) or by oxidation of the hemiacetals (from reaction of benzyl alcohols with benzaldehydes).

Table 3. Catalytic oxidation of various alcohols over CAPS-CuO with air ${ }^{[a]}$

Entry Selectivity [\%]


8

9

10

11

12

$13^{[\mathrm{b}]}$

14

15
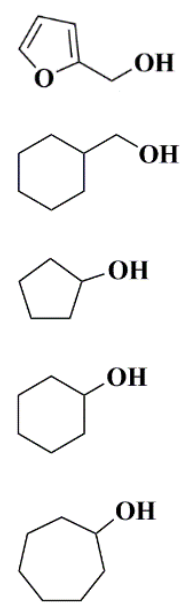

$\sim^{\mathrm{OH}}$

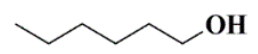

$\Upsilon^{0}$

7

27

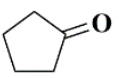

3

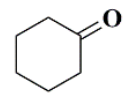

7

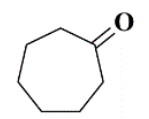

$>99$

$>99$

6
$>99$

99

98

$>99$

$>99$

96

$>99$

$>99$

[a] Reaction conditions: Alcohol $(1 \mathrm{mmol})$, anisole $(0.1 \mathrm{mmol})$, toluene $(3 \mathrm{~mL})$, catalyst $(60 \mathrm{mg})$, $24 \mathrm{~h}, 100^{\circ} \mathrm{C}$, atmospheric air. [b] $80^{\circ} \mathrm{C}$.

\subsection{Mechanism of oxidation}

The XRD measurements showed that part of the $\mathrm{CuO}$ catalyst was reduced during reaction initially forming $\mathrm{Cu}_{2} \mathrm{O}$ and eventually metallic $\mathrm{Cu}$. The amount of reduced copper increased with the reaction time (SI Fig. 5b). Copper was reoxidized to $\mathrm{CuO}$ after regeneration by calcining at $300{ }^{\circ} \mathrm{C}$ for $30 \mathrm{~min}$ (SI Fig. 6). The observation of reduced copper in experiments with high conversion and the lack of $\mathrm{Cu}(0)$ in reactions with low conversion (i.e. under atmosphere other than air), suggests that redox cycling of active copper centers may be involved in the reaction mechanism.

A simplified mechanism for $\mathrm{CuO}$ catalyzed benzaldehyde formation under aerobic conditions is proposed in Scheme $\mathbf{1}$ in agreement with reports by Abad et al. and Fristrup et al. ${ }^{49}$ In the cycle, benzyl alcohol adsorbs to a copper site forming a metal-alkoxide intermediate. The 
hydroxy proton is abstracted by a neighbouring surface oxygen. Subsequently, $\beta-\mathrm{H}$ elimination facilitated by $\mathrm{Cu}(\mathrm{II})$ generates $\mathrm{Cu}(\mathrm{II})$ hydride and a benzyl carbocation intermediate followed by aldehyde formation. In the final step, atmospheric oxygen reacts with the hydride forming peroxide anion and regenerating the catalytic $\mathrm{Cu}(\mathrm{II})$ site. Reaction of the peroxide anion with a second hydride reduces it further to hydroxide anions. These hydroxide anions react in an offcycle mechanism with the protonated surface oxygen to produce water as the only by-product. Further studies have been initiated to elucidate the mechanistic pathway. The observed reduction of the $\mathrm{CuO}$ may arise from deprotonation of the hydride intermediate forming $\mathrm{Cu}(0)$ and subsequent conproportionation of $\mathrm{Cu}(0)$ and adjacent $\mathrm{Cu}(\mathrm{II})$ to from $\mathrm{Cu}(\mathrm{I})$.

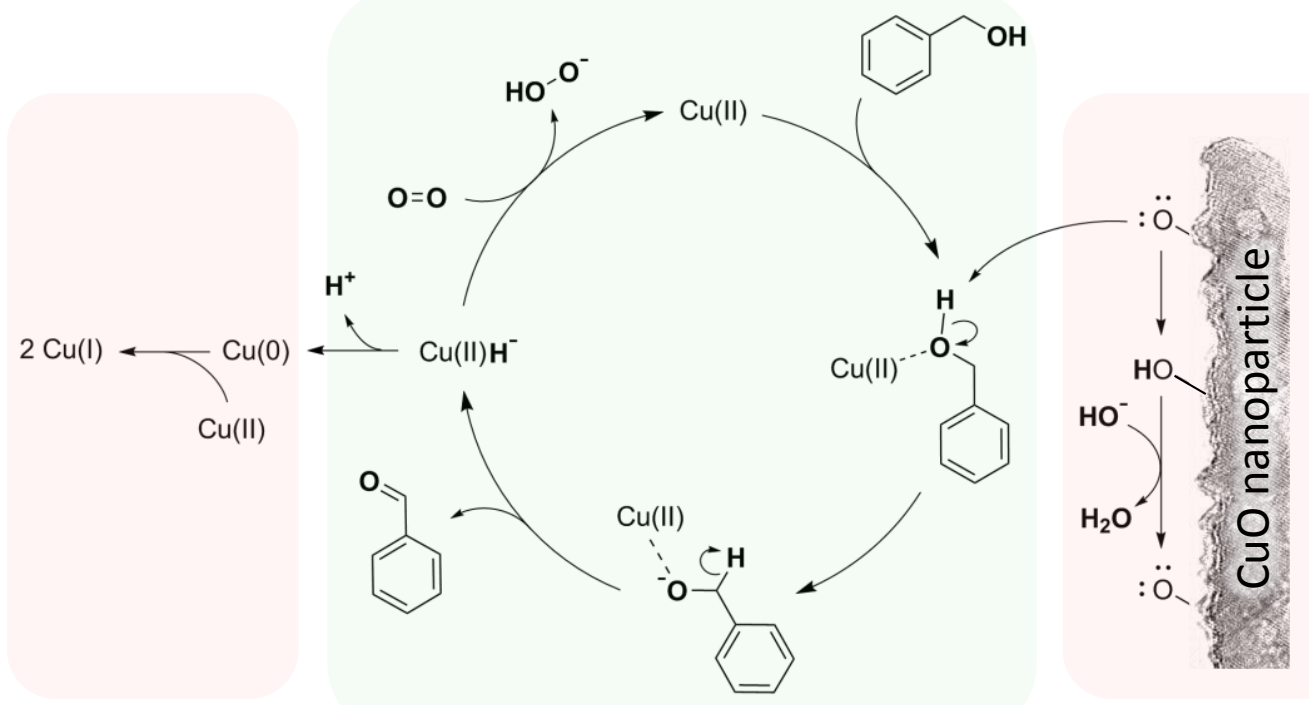

Scheme 1. Simplified reaction mechanism for the $\mathrm{CuO}$ catalyzed oxidation of benzyl alcohol with atmospheric oxygen.

\subsection{Reaction heterogeneity}

To assess the heterogeneity of the reaction, a hot filtration test was performed after 8 and $24 \mathrm{~h}$ of the reaction with the CAPS-CuO catalyst (Fig. 9). After removal of the catalyst after $8 \mathrm{~h}$ of reaction, no further conversion was observed indicating that active species did not leach to the 
reaction liquor. However, after $24 \mathrm{~h}$ of reaction a trace amount of copper was indeed observed by ICP-MS in the reaction phase (SI Fig. 1). Interestingly, the leached copper species did to not catalyze the reaction homogeneously when excess benzyl alcohol was added to the filtrate, and the yield remained on the same level $(2-3 \%)$ as found in the blank experiment after $48 \mathrm{~h}$ of reaction (Table 1, entry 11). These findings clearly ruled out that leached copper species contributed to the oxidation of benzyl alcohol.

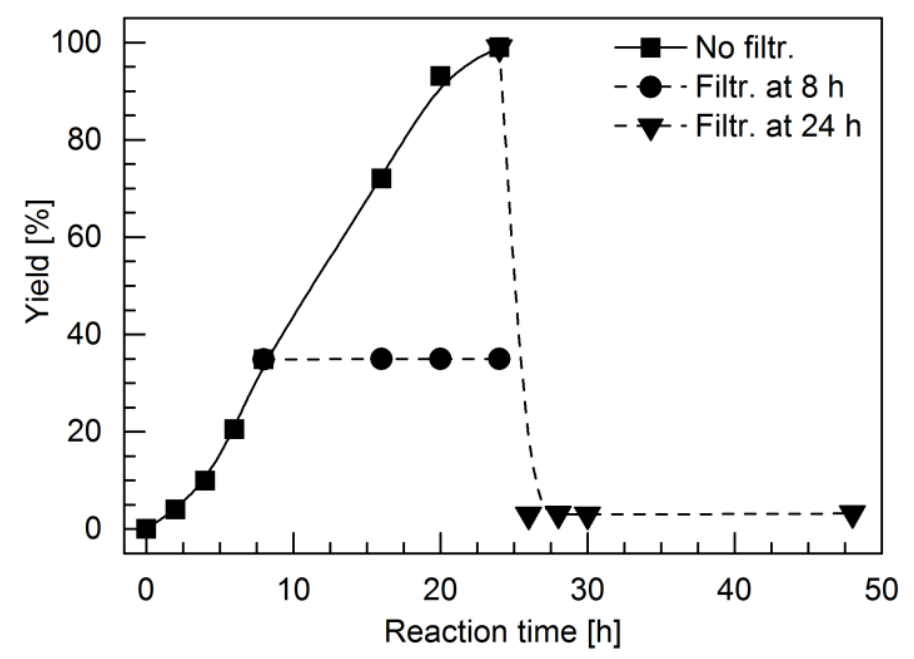

Fig. 9. Yields from separate hot filtration experiments where the CAPS-CuO catalyst was removed by filtration and the reaction filtrate allowed to react further. $(\bullet)$ : Catalyst removed after $8 \mathrm{~h}$. ( $\mathbf{\nabla})$ : Catalyst removed after $24 \mathrm{~h}$ followed by addition of $1 \mathrm{mmol}$ substrate and continued reaction for another 24 h. (-): Results with catalyst from Fig. 8 (for comparison). Reaction conditions: Benzyl alcohol $(1 \mathrm{mmol})$, anisole $(0.1 \mathrm{mmol})$, toluene $(3 \mathrm{~mL})$, catalyst $(60$ $\mathrm{mg}), 100^{\circ} \mathrm{C}$, atmospheric air.

\subsection{Reusability studies}

An imperative feature of heterogeneous catalysts is their recovery from the reaction medium and reuse. The prepared CAPS-CuO catalyst could easily be separated from the reaction mixture by filtration followed by drying $\left(120^{\circ} \mathrm{C}, 1 \mathrm{~h}\right)$ and reused in the oxidation of benzyl alcohol as 
shown in Fig. 10. In the second reaction run the catalytic performance remained unchanged with conversion and yield of $>99 \%$, showing the apparent stability of the prepared catalyst. However, during further reuse the catalyst lost activity leading to gradual decrease in conversions to 53,7 and $2 \%$ in the successive third, fourth and fifth reaction run, respectively. Notably, the conversion after the fifth run $(2 \%)$ was equal to the conversion obtained without the presence of the catalyst (Table 1, entry 11).

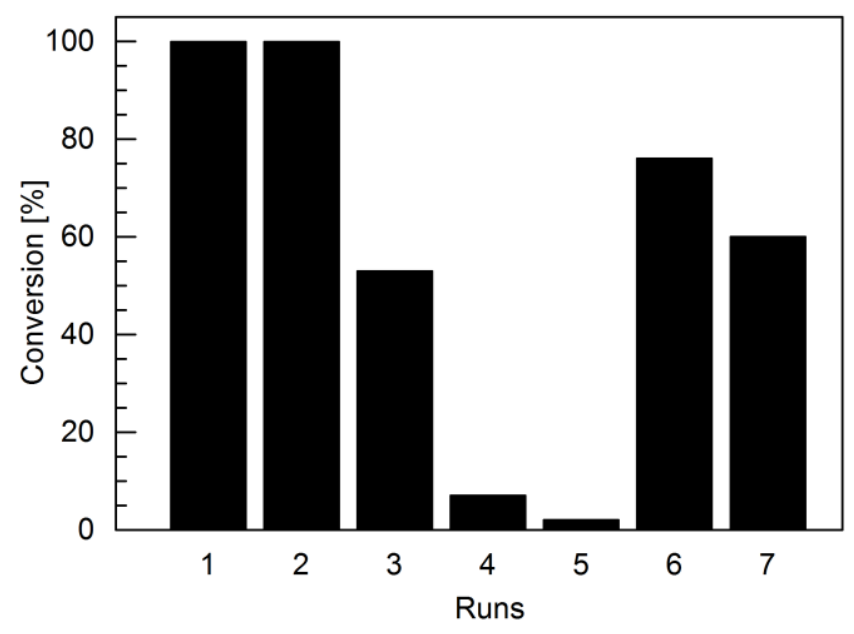

Fig. 10. Reuse of the CAPS-CuO catalyst in the oxidation of benzyl alcohol with intermediate drying at $120^{\circ} \mathrm{C}$ for $1 \mathrm{~h}$ (until run 5). Reaction conditions: Benzyl alcohol (1 mmol), anisole (0.1 $\mathrm{mmol})$, toluene $(3 \mathrm{~mL})$, catalyst $(60 \mathrm{mg}), 24 \mathrm{~h}, 100^{\circ} \mathrm{C}$, atmospheric air.

From the findings of TGA (SI Fig. 7), it was evident that the spent catalyst lost $11 \mathrm{wt} \%$ when treated at $250{ }^{\circ} \mathrm{C}$ in air. This suggested that carboxolate deposits had accumulated on the active sites of $\mathrm{Cu}$ restricting the accessibility to the substrate. This was further supported by ATR-FTIR where a weak absorbance between 1300 and $1650 \mathrm{~cm}^{-1}$ was observed (SI Fig. 8). Hence, if the catalyst was pre-heated at $600{ }^{\circ} \mathrm{C}$ for $30 \mathrm{~min}$ before being reused again in a sixth reaction run the catalyst regained a significant part of its original activity and $76 \%$ conversion 
was obtained (Fig. 10). However, significant decrease in activity to about $60 \%$ conversion (99\% selectivity) was again obtained after yet another reaction run (seventh run), possibly due to agglomeration of copper oxide particles facilitated by the thermal regeneration process.

Another reusability study was performed with fresh catalyst and intermediate reactivation at $300{ }^{\circ} \mathrm{C}$ for $45 \mathrm{~min}$ (instead of $600{ }^{\circ} \mathrm{C}$ for $30 \mathrm{~min}$ ) (Fig. 11). As expected, the catalyst demonstrated here almost consistent performance for four consecutive catalytic runs with consistent conversion and selectivity $\geq 97 \%$ (the slight decrease in conversion in the third run is attributed to an experimental error).

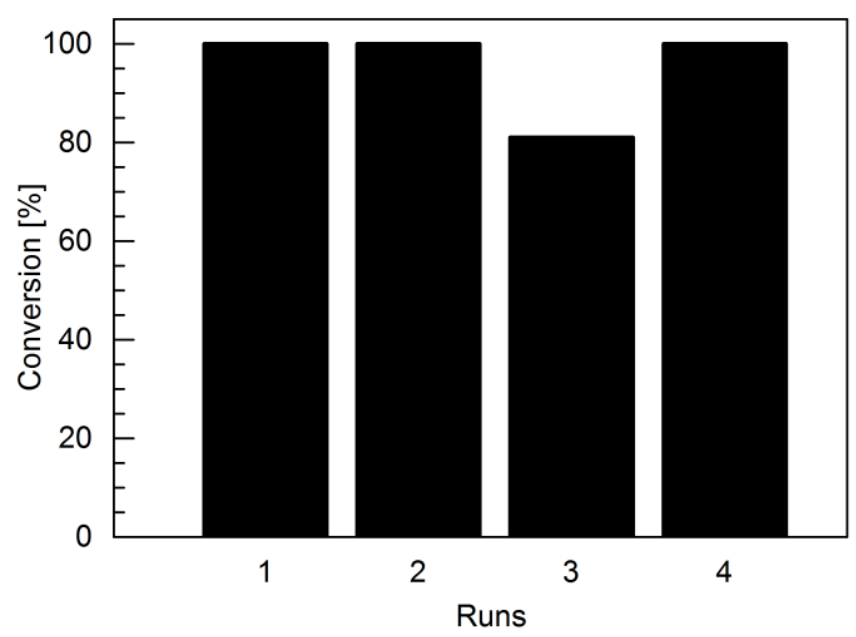

Fig. 11. Reuse of the CAPS-CuO catalyst in the oxidation of benzyl alcohol with intermediate thermal re-activation at $300{ }^{\circ} \mathrm{C}$ for $45 \mathrm{~min}$. Reaction conditions: Benzyl alcohol (1 mmol), anisole $(0.1 \mathrm{mmol})$, toluene $(3 \mathrm{~mL})$, catalyst $(60 \mathrm{mg}), 24 \mathrm{~h}, 100{ }^{\circ} \mathrm{C}$, atmospheric air.

\section{Conclusions}

Two types of copper oxide nanoparticles (CAPS-CuO and MES-CuO) were synthesized using the different buffers CAPS and MES, respectively, thoroughly characterized by imaging spectroscopy and diffraction techniques, and tested for the oxidation of benzyl alcohol to 
benzaldehyde with air at atmospheric pressure. Synthesis with the two buffers had a significant effect on the catalytic performance of the copper nanoparticles, and CAPS-CuO (CAPS buffer) gave better product yields than MES-CuO (MES buffer). HR-TEM characterization of the catalysts revealed a difference in exposed crystal facets with CAPS-CuO exposing mainly stable [001] facets possibly limiting its degradation during reaction. In addition, Rietveld refinements of $\mathrm{XRD}$ data showed a clear difference in $\mathrm{CuO}$ reduction between the catalysts, which likely influenced their catalytic performance.

The versatility of the oxidation reaction with CAPS-CuO was demonstrated by transforming benzylic, alicyclic and unsaturated alcohols to the desired products with exceptional selectivity (>99\%). A significant increase in conversion was observed with benzyl alcohols containing electron donating groups $\left(p-\mathrm{OCH}_{3}\right.$ and $\left.p-\mathrm{CH}_{3}\right)$ compared to electron withdrawing groups $\left(p-\mathrm{Cl}\right.$ and $\left.p-\mathrm{CF}_{3}\right)$, suggesting a linear free energy relationship between activity and $\sigma^{+}$. Results from competitive oxidation of benzyl alcohols supports that $\alpha-\mathrm{C}-\mathrm{H}$ dissociation results in the formation of a stable benzylic carbocation intermediate. Moreover, the activity towards alicyclic alcohols was shown to follow the ring tension leaving larger rings more reactive. Importantly, CAPS-CuO was further found to be stable and reusable if thermally regenerated. Further studies, including kinetic isotopic studies and Hammett correlations, are in progress to elucidate the reaction mechanism in more detail.

The use of $\mathrm{CuO}$ as an efficient, inexpensive and selective heterogeneous catalyst for the oxidative dehydrogenation of alcohols proposes a new sustainable reaction protocol for carbonyl compound synthesis.

Supporting Information. Supplementary data were supplied in Supporting Information. 


\section{AUTHOR INFORMATION}

\section{Corresponding Author}

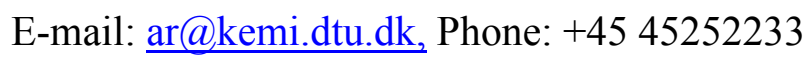

\section{ACKNOWLEDGMENT}

Financial support by the UNIK research initiative Catalysis for Sustainable Energy and Lundbeck (R45-A3878) for the PhD study of R.P and C.E., respectively, is acknowledged. Authors would like to express their gratitude to Jonas Andersen for work on Rietveld refinements and Dr. Leonhard Schill for assistance with XPS acquisition.

\section{REFERENCES}

${ }^{1}$ G. Tojo, M. Fernandez, In Oxidation of Alcohols to Aldehydes and Ketones: A Guide to Current Common Practice; Springer: New York, 2006.

2 a) M. A. Halcrow, P. F. Knowles, S. E. V. Phillips, In Handbook on Metalloproteins; I. Bertini, A. Sigel, H. Sigel., Eds.; Marcel Dekker Inc: New York, 2001, p 709. b) Q. Jr. Lawrence, B. T. William, Nature 2008, 455, 333.

3 a) S. S. Shannon, Science 2005, 309, 1824; b) J. Muzart, Tetrahedron 2003, 59, 5789; c) J. Muzart, Chem. Asian J 2006, 1, 508; d) T.F. Blackburn, J. Schwartz, J. Chem. Soc., Chem. Commun. 1977, 157; f) C. Liu, S. Tang, A. Lei, Chem. Commun. 2013, 49, 1324.

${ }^{4}$ G. Cainelli, G. Cardillo, In Chromium Oxidations in Organic Chemistry; Springer: Berlin.

5 S. Zhang, L. Xu, M. L. Trudell, Synthesis 2005, 11, 1757. 
${ }^{6}$ G. B. Shul'Pin, Y. N. Kozlov, L. S. Shul'Pina, T.V. Strelkova, D. Mandelli, Catal. Lett. 2010, 138, 193.

${ }^{7}$ R. A. Sheldon, J. K. Kochi, In Metal-Catalysed Oxidations of Organic Compounds, Academic Press, New York, 1981.

${ }^{8}$ T. Mallat, A. Baiker, Chem. Rev. 2004, 104, 3037.

${ }^{9}$ D. L. Pradeep, R. W. Smita, G. Harsh, P. P. Hankare, J. Korean Chem. Soc. 2012, 56, 539.

${ }^{10}$ J. Mielby, R. Poreddy, C. Engelbrekt, S. Kegnæs; Chin. J. Catal. 2014, 35, 670.

${ }^{11}$ Z. Junjiang, L. F. Joaquim, L. F. Jose, T. Arne, Chem. Eur. J. 2011, 17, 7112.

${ }^{12}$ S. J. Tauster, S.C. Fung, R.T. K. Baker, J. A. Horsley, Science 1981, 211, 1121.

${ }^{13}$ C. Parmeggiani, F. Cardona, Green Chem. 2012, 14, 547.

${ }^{14}$ G.C. Bond, P.A. Sermon, G. Webb, D. A. Buchanan, P. B. Well, J. Chem. Soc. Chem. Commun.1973, 444.

${ }^{15}$ G. J. Hutchings, J. Catal. 1985, 96, 292.

${ }^{16}$ M. Haruta, N. Yamada, T. Kobayashi, S. Ijima, J. Catal. 1989, 115, 301.

${ }^{17}$ L. Prati, M. Rossi, J. Catal. 1998, 176, 552.

${ }^{18}$ Z. Hou, N. Theyssen, A. Brinkmann, K.V. Klementiev, W. Grünert, M. Bühl, W. Schmidt, B. Spliethoff, B. Tesche, C. Weidenthaler, W. Leitner, J. Catal. 2008, 258,315.

${ }^{19}$ A.S.K. Hashmi, Chem. Rev. 2007, 107, 3180. 
${ }^{20}$ Guideline on the specification limits for residues of metal catalysts from the European Agency for the Evaluation of Medicinal Products (EMEA), 2007 (http://www.emea.europa.eu). According to the guideline, only iron residues are considered entirely unproblematic. The limit for the total amount of platinoid-group metals is $5 \mathrm{mg} \mathrm{kg}^{-1}$ (for dosages of up to $10 \mathrm{~g}$ per day). Compliance to this limit is usually assured by post-reaction scavenging/purification.

${ }^{21}$ (a) C. E. Garrett, K. Prasad, Adv. Synth. Catal. 2004, 346, 889; (b) C. J. Welch, W. J. Albaneze, W. R. Leonard, M. Biba, J. DaSilva, D. Henderson, B. Laing, D. J. Mathre, S. Spencer, X. Bu, T. Wang, Org. Process Res. Dev. 2005, 9, 198; (c) J. T. Bien, G. C. Lane, M. R. Oberholzer, Top. Organmet. Chem.2004, 6, 263.

22 H. Wang, F. Weibin, H. Yue, W. Jianguo, N. K. Junko, T. Takshi, J. Catal. 2013, 299,10.

23 (a) S. Enthaler, K. Junge, M. Beller, Angew. Chem., Int. Ed. 2008, 47, 3317; (b) E. Nakamura, K. Sato, Nat. Mater. 2011, 10, 158.

${ }^{24}$ R. Poreddy, E.J. Garcia-Suarez, A. Riisager, S. Kegnæs, Dalton Trans. 2014, 43, 4255.

25 (a) A. Alexakis, J. E. Backvall, N. Krause, O. Pamies, M. Dieguez, Chem. Rev. 2008, 108, 2796; (b) L. M. Stanley, M. P. Sibi, Chem. Rev. 2008, 108, 2887; (c) M. Meldal, C. W. Tornøe, Chem. Rev. 2008, 108, 295; (d) F. Collet, C. Lescot, P. Dauban, Chem. Soc. Rev. 2011, 40, 1926.

26 (a) D. Yu, Y. G. Zhang, Proc. Natl. Acad. Sci. U. S. A 2010, 107, 20184; (b) D. Yu, Y. G. Zhang, Adv. Synth. Catal. 2011, 353, 163; (c) Y. G. Zhang, L. W. Chen, T. Lu, Adv. Synth. Catal. 2011, 353, 1055. (d) A. Martínez-Asencio, D. J. Ramon, M. Yus, Tetrahedron 2011, 67, 3140. 
27 (a) C. Bolm, J. Legros, J. Le Paih, L. Zani, Chem. Rev. 2004, 104, 6217; (b) B. D. Sherry, A. Fuerstner, Acc. Chem. Res. 2008, 41, 1500; (c) A. Correa, M. O. Garcia, C. Bolm, Chem. Soc. Rev. 2008, 37, 1108; (d) R. H. Morris, Chem. Soc. Rev.2009, 38, 2282; (e) C. L. Sun, B. J. Li, Z. J. Shi, Chem. Rev. 2011, 111, 1293; (f ) M. O. Garcia, Angew. Chem., Int. Ed. 2011, 50, 2216; (g) A. C. Gonzalez, K. Yoshida, R. Luque, P. L. Gai, Green Chem. 2010, 12, 1281.

${ }^{28}$ O. David, M. B. Alina, A. R. Antonia, G. Walter, L. Rafael, K. C. Oliver, Green Chem. 2013, 15, 1530.

${ }^{29}$ K. Qiang, Z. Yugen, Green Chem. 2012, 14, 1016.

${ }^{30}$ 1. I. E. Marko, M.Tsukazaki, P. R. Giles, S. M. Brown, C.J.Urch, Angew. Chem. Int. Ed. Engl. 1997, 36, 2208.

${ }^{31}$ F. Zaccheria, N. Ravasio, R. Psaro, A. Fusi, Chem. Eur. J. 2006, 12, 6426.

${ }^{32}$ D. P. Cristina, F. Ermelinda, R. Michele J. Catal. 2008, 260, 384.

${ }^{33}$ R. M. Rioux, M. A. Vannice, J. Catal. 2005, 233,147.

34 E. Christian, M. Philip, A. Jonas, Z. Lijuan, S. Kenny, L. Bin, H. Jun, Z. Jingdong, J. Nanopart. Res. 2014, 16, 2562.

${ }^{35}$ Z. Zhongping, S. Haiping, S. Xiaoqiong, L. Dongfei, Y. Haidong, H. Mingyong, Adv. Mater. $2005,17,1,42$.

${ }^{36}$ Y. Li-Xia, J. Z. Ying, T. Hau, L. Liang, Z. Ling, Mater. Chem. Phys. 2008, 112, 442. 
${ }^{37}$ L. Jinping, H. Xintang, L. Yuanyuan, K. M. Sulieman, H. Xiang, S. Fenglou, Cryst. Growth \& Design 2006, 6, 1690.

${ }^{38}$ L. Jing, J. Jun, D. Zhao, Z. H. Shao, Y. H. Zhi, W. Li, W. Chao, H. C. Li, L.Yu, T. G. Van, L. S. Bao, J. Colloid Interface Sci. 2012, 384,1.

${ }^{39}$ J. F. Xu, W. Ji, Z. X. Shen, S. H. Tang, X. R. Ye, D. Z. Jia, X. Q. Xin, J. Solid State Chem. 1999, 147, 516.

${ }^{40}$ A. B. Pereda, L. T. U. De, G. N. J. Illan, L. A. Bueno, V. J. R. Gonzales, Appl. Catal. B: Environ. 2014, 147, 420.

${ }^{41}$ N. S. McIntyre, M. G. Cook, Anal. Chem. 1975, 47, 2208.

42 http://www.lasurface.com, accessed on 13th May 2014.

${ }^{43}$ P. Juyun, L. Kyounga, D. R. Rex, C. K. Yong, Bull. Korean Chem. Soc. 2011, 32, 3395.

${ }^{44}$ M. Shimokawabe, H. Asakawa, N. Takezawa, Appl. Catal.1990, 59, 45.

${ }^{45}$ W. P. Dow, Y. P. Wang, T. J. Huang, J. Catal. 1996, 160, 155.

${ }^{46}$ C. J. G. Van der Grift, A. Mulder, J. W. Geus, Appl. Catal. 1990, 60, 181.

${ }^{47}$ S. D. Robertson, B. D. Mcnicol, J. H. Debaos, S. C. Kloet, J. W. Jenkins, J. Catal. 1975, 37, 424.

${ }^{48}$ K. I. Shimizu, S. Kenji, S. Kyoichi, S. Atsushi, Chem. Eur. J. 2009, 15, 2341. 
49 (a) A. Abad, A. Corma, H. Garcia, Chem. Eur. J., 2008, 14, 212; (b) P. Fristrup, L. B.

Johansen, C. H. Christensen, Catal. Lett., 2008, 120, 184 